\title{
MODELLING SIMULTANEOUS REMOVAL OF TRICHLORFON AND GLUCOSE IN A HYBRID BIOREACTOR CONTAINING MAGNETICALLY IMMOBILIZED BIOMASS
}

\author{
Guang Hao Chen ${ }^{1}$, Hiroaki Ozaki ${ }^{2}$, and Yutaka Terashima ${ }^{2}$ \\ ${ }^{I}$ Department of Civil \& Structural Engineering, Hong Kong University of Science \& \\ Technology, Clear Water Bay, Kowloon, Hong Kong \\ ${ }^{2}$ Department of Environmental Engineering, Kyoto University, Yoshidahonmachi, \\ Sakyo-Ku, Kyoto 606, Japan
}

\begin{abstract}
Trichlorfon is one of the representative organophosphate insecticides widely used in agricultural and veterinary practices. Due to toxic and carcinogenic characteristics of the residues in the environment, remediation of such residues is necessary. To biodegrade trichlorfon effectively, a source of easily biodegradable substrates is needed for fulfilling the co-metabolism requirement of trichlorfon-removing bacteria. This paper focused on a simultaneous removal of trichlorfon and the glucose added as the source of the substrate. A hybrid bioreactor consisting of suspended and magnetically immobilized biomass was employed to study the removal efficiencies of both the substances. A mathematical model was developed in this paper in order to extensively evaluate the removal performance of both the biomass under various removal conditions. Comparisons between model predictions and experimental results showed that the proposed model was able to satisfactorily predict the simultaneous removal efficiency of trichlorfon and glucose in the hybrid bioreactor. This study also indicated that the suspended biomass plays a more important role in removing both the substances than the immobilized biomass when the trichlorfon- and glucose-removing bacteria completely coexist in both the biomass phases. To increase the removal contribution of the immobilized biomass, the hybrid bioreactor is recommended to deal with such complex wastewaters that contain much slowly biodegradable pollutants having a high diffusivity.
\end{abstract}

\section{KEYWORDS}

Simultaneous removal of trichlorfon and glucose; hybrid bioreactor; mathematical modelling; suspended biomass; magnetically immobilized biomass.

\section{INTRODUCTION}

Contamination of the environment by organophosphate insecticides is an important environmental issue because their residues in natural water have been found to be toxic and carcinogenic (International Agency for Research on Cancer, 1983). Due to the fast development of golf courses in some nations, this contamination problem has been greatly concerned (Primi et al., 1994). To control the problem, remediation of the residues from the environment is desired. It has been found that trichlorfon, a widely used organophosphate insecticide, can be slowly biodegradable (Orus and Arco, 1991). Such biodegradation usually requires the presence of an easily biodegradable substrate in order to meet the microbial cometabolism requirement of trichlorfon degrading bacteria (Horvath, 1972). Therefore, to obtain an effective removal of trichlorfon, addition of an easily biodegradable substrate is necessary. It is obvious that such a substrate should be simultaneously removed with trichlorfon so as to prevent any secondary pollution from addition of the substrate in a trichlorfon degradation process.

A hybrid biotreatment system consisting of both suspended and attached biomass is expected to be able to achieve a simultaneous removal of these two substances effectively (Chen, 1995). In order to extensively 
evaluate the removal performance of both the biomass in the system, model simulation on the removal efficiency under various removal conditions is usually sought. A couple of mathematical models for hybrid systems have been developed for this purpose under an assumption that slowly growers mainly existed in the attached phase of biomass, that is, the slowly biodegradable substances were mainly removed by the attached biomass (Chen, 1995; Chen et al., 1997). Such models may not be appropriate when a substantial amount of slowly growers are actually available in the suspended phase. Therefore, this paper is aimed at developing a more comprehensive model to improve the previous models by considering the simultaneous removal of trichlorfon and glucose in both the suspended phase and the attached phase.

Verification of the proposed model was made through comparisons between the model predictions and experimental results obtained from a hybrid bioreactor containing magnetically immobilized biomass. The introduction of such immobilized biomass is to efficiently investigate the mass ratio of the suspended biomass to the attached biomass on the simultaneous removal efficiency, which is one of the most important influencing factors in a hybrid system (Chen et al., 1997).

\section{MODEL DEVELOPMENT}

It is considered in this paper that both the trichlorfon- and glucose-removing bacteria completely coexist in the suspended as well as the attached biomass phases in a hybrid bioreactor. Therefore, the bacteria species in these phases may not be necessarily divided into respective removing groups in the course of modelling. The attached biomass is assumed to be uniform with a constant density and the concentration of dissolved oxygen (DO) in the reactor to be kept in a relatively high level so that oxygen limitation can be avoided (Chen et al., 1994). Under such considerations, mass balance of trichlorfon and glucose in a steady-state hybrid bioreactor can be taken as follows:

\section{Suspended phase}

$$
\begin{array}{ll}
\text { Trichlorfon } & Q\left(S_{o t}-S_{t}\right)=\frac{K_{t m s} S_{t}}{K_{t s}+S_{t}} \cdot \frac{C}{K_{o}+C} X_{m} V+A J_{t} \\
\text { Glucose } & Q\left(S_{o g}-S_{g}\right)=\frac{K_{g m s} S_{g}}{K_{g s}+S_{g}} \cdot \frac{C}{K_{o}+C} X_{m} V+A J_{g}
\end{array}
$$

where $A$ is the surface area of the attached phase $\left(\mathrm{cm}^{2}\right) ; C$ is the oxygen concentration in the bulk liquid phase $(\mathrm{mg} / \mathrm{L}) ; J_{\mathrm{g}}$ and $J_{t}$ are the glucose and trichlorfon removal fluxes by the attached biomass $\left(\mathrm{mg} / \mathrm{cm}^{2} /\right.$ day); $K_{g m s}$ and $K_{t m s}$ are the maximum specific removal rates of glucose and trichlorfon (1/day); $K_{g s}, K_{t s}$, and $K_{o}$ are the saturation constants of glucose, trichlorfon, and oxygen $(\mathrm{mg} / \mathrm{L})$, respectively; $Q$ is the flow rate $\left(\mathrm{m}^{3} /\right.$ day); $S_{o g}$ and $S_{g}$ are the influent and effluent glucose concentrations $(\mathrm{mg} / \mathrm{L}) ; S_{o t}$ and $S_{t}$ are the influent and effluent trichlorfon concentrations $(\mathrm{mg} / \mathrm{L}) ; V$ is the reactor volume $\left(\mathrm{m}^{3}\right) ; X_{m}$ is the concentration of the suspended biomass (mg SS/L). In the above equations, endogenous respiration and production of secondary substrates from the lysis of dead biomass are neglected, and the values of the kinetic parameters within the attached phase are assumed to be the same as those in the suspended phase.

\section{Attached phase}

a) in the diffusion layer on the phase surface

$$
\begin{array}{ll}
\text { Trichlorfon } & D_{w t} \frac{\partial^{2} S_{t s}}{\partial Z^{2}}=0 \\
\text { Glucose } & D_{w g} \frac{\partial^{2} S_{g s}}{\partial Z^{2}}=0 \\
\text { Oxygen } & D_{w c} \frac{\partial^{2} C_{s}}{\partial Z^{2}}=0
\end{array}
$$


b) within the phase

$$
\begin{array}{ll}
\text { Trichlorfon } & D_{f t} \cdot \frac{\partial^{2} S_{t f}}{\partial Z^{2}}=\frac{K_{t m s} \cdot S_{t f}}{K_{t s}+S_{t f}} \cdot \frac{C_{f}}{K_{o}+C_{f}} \cdot X_{f} \\
\text { Glucose } & D_{f g} \cdot \frac{\partial^{2} S_{g f}}{\partial Z^{2}}=\frac{K_{g m s} \cdot S_{g f}}{K_{g s}+S_{g f}} \cdot \frac{C_{f}}{K_{o}+C_{f}} \cdot X_{f} \\
\text { Oxygen } & D_{f c} \cdot \frac{\partial^{2} C_{f}}{\partial Z^{2}}=\left(1-P Y_{g}\right) D_{f g} \cdot \frac{\partial^{2} S_{g f}}{\partial Z^{2}}+\left(1-P Y_{t}\right) D_{f t} \cdot \frac{\partial^{2} S_{t f}}{\partial Z^{2}}
\end{array}
$$

where $C_{f}$ and $C_{s}$ are the oxygen concentrations in the attached phase and in the diffusion layer and (mg/L); $D_{f c}, D_{f g}$, and $D_{f t}$ are the diffusion coefficients of oxygen, glucose, and trichlorfon within the attached phase ( $\mathrm{cm}^{2} /$ day), respectively; $D_{w c}, D_{w g}$, and $D_{w t}$ are the diffusion coefficients of oxygen, glucose, and trichlorfon in the bulk liquid phase ( $\mathrm{cm}^{2} /$ day), respectively; $P$ is the conversion coefficient between COD and biomass (mg $\mathrm{COD} / \mathrm{mg}$ VSS); $S_{g f}$ and $S_{t f}$ are the concentrations of glucose and trichlorfon within the attached phase $(\mathrm{mg} / \mathrm{L}) ; S_{g s}$ and $S_{t s}$ are the concentrations of glucose and trichlorfon in the diffusion layer $(\mathrm{mg} / \mathrm{L}) ; X_{f}$ is the biomass density in the attached phase $\left(\mathrm{mg} \mathrm{SS} / \mathrm{cm}^{3}\right) ; Y_{g}$ and $Y_{t}$ are the yield coefficients of glucose and trichlorfon (mg VSS/mg COD); and $Z$ represents two depths: 1 ) from the surface of the diffusion layer to the attached biomass surface ( 0 to $\left.L_{o}\right)$ and 2) from the attached phase surface to the bottom of the attached phase $\left(L_{o}\right.$ to $\left.L_{o}+L_{f}\right)(\mathrm{cm})$.

\section{MODEL ANALYSIS}

\section{Approach for model simulation}

To simplify a numerical analysis of the proposed model, it is assumed that the oxygen concentration profile within the attached phase was mainly controlled by glucose oxidation because the concentration of glucose was significantly higher than trichlorfon in this study. Thus, calculation of the glucose and oxygen concentration profile in the diffusion layer and within the attached phase can be separated from the calculation of trichlorfon which is conducted lately based on the oxygen profile obtained in the glucose profile calculation. It is also assumed that a TOC unit could be used to quantify glucose as the glucose concentration in this study was about five times higher than that of trichlorfon and 1 trichlorfon is only equal to 0.19 TOC while 1 glucose gives 0.4 TOC. Based on these assumptions, the following numerical analysis procedure was developed for solving the model: 1) A value of the $S_{g}$ is given by the rule of golden section that is applied to Eq. (2); 2) With the given values of $C$ and $S_{g}$, the $J_{g}\left(=\left.D_{w g} \frac{\partial S_{g s}}{\partial Z}\right|_{z=0}\right)$ can be calculated from the $S_{g}$ profile in the diffusion layer. The profile calculation starts from the surface of the diffusion layer to the bottom of the attached phase under a boundary condition that the fluxes of oxygen and glucose at the bottom are zero. In this calculation discretization of Eqs. (4), (5), (7), and Eq. (8) neglecting the last term of its right hand side are proceeded to form coupled ordinary differential equations from which the concentration profiles of glucose and oxygen can be calculated; 3) An iteration of the $S_{g}$ and $C_{f}$ is introduced in step 2) for obtaining a stable result of the profile because of the non-linearity of Eqs. (7) and $(8) ; 4)$ If the $J_{g}$ and the $S_{g}$ do not satisfy Eq. (2), step 1), 2), and 3) will be repeated until acceptable values of the $S_{g}$ and $J_{g}$ for Eq. (2) is identified; 5) Following the above steps the $S_{t}$ can also be calculated from the Eqs. (1), (3) and (6) after the oxygen profile has been determined in the glucose calculation.

\section{Determination of Parameter Value}

To conduct the numerical simulation of the model, the values of the parameters employed in the model should be determined. There are three types of parameters included in this model: 1) substances removal related kinetic parameters such as $K_{g m s}, K_{t m s}, K_{g s}, K_{o}$, and $\left.K_{t s} ; 2\right)$ physical, chemical, and biochemical properties related parameters such as $D_{w}, D_{f}, Y$, and $P$; and 3) bioreactor configuration and operational conditions related parameters such as $A, Q, V, S_{o}, C, X_{m}, X_{f}, L_{f}$, and $L_{o}$. The first group parameters are the most important ones that directly govern the removal capacity of the system. Therefore, those parameters 
were identified through a batch test using cultivated biomass with trichlorfon and glucose. The cultivation of biomass started with seeding material taken from a sewage treatment plant in Kyoto city of Japan. A fill and draw batch cultivation was carried out for at least two months with the artificial wastewater composed of 25 $\mathrm{mg} / \mathrm{L}$ trichlorfon, $1000 \mathrm{mg} / \mathrm{L}$ glucose, and sufficient trace nutrients.

The batch test was conducted with initial concentrations of glucose at $120 \mathrm{mg}$ TOC/L, measured by a TOC analyzer (Shimadsu), and of trichlorfon at $25 \mathrm{mg} / \mathrm{L}$, measured by a HPLC instrument (Yanagimoto) adapted from Samuelsen (1987). The DO level in the test was controlled above $5 \mathrm{mg} / \mathrm{L}$. Thus, oxygen limitation was not considered (Chen et al., 1994). Figure 1 shows the experimental results of the test. The kinetic parameters, except for the saturation constant of oxygen which was assumed to be $0.1 \mathrm{mg} / \mathrm{L}$ in this paper (Chen et al., 1988), were identified from the batch test data and the following Eqs (9) and (10), as shown in Fig. 1

$$
\begin{array}{ll}
\text { Trichlorfon } & \frac{d S_{t}}{d t}=\frac{K_{t m s} \cdot S_{t}}{K_{t s}+S_{t}} X_{m} \\
\text { Glucose } & \frac{d S_{g}}{d t}=\frac{K_{g m s} \cdot S_{g}}{K_{g s}+S_{g}} X_{m}
\end{array}
$$

where $t$ is the reaction time (hr).

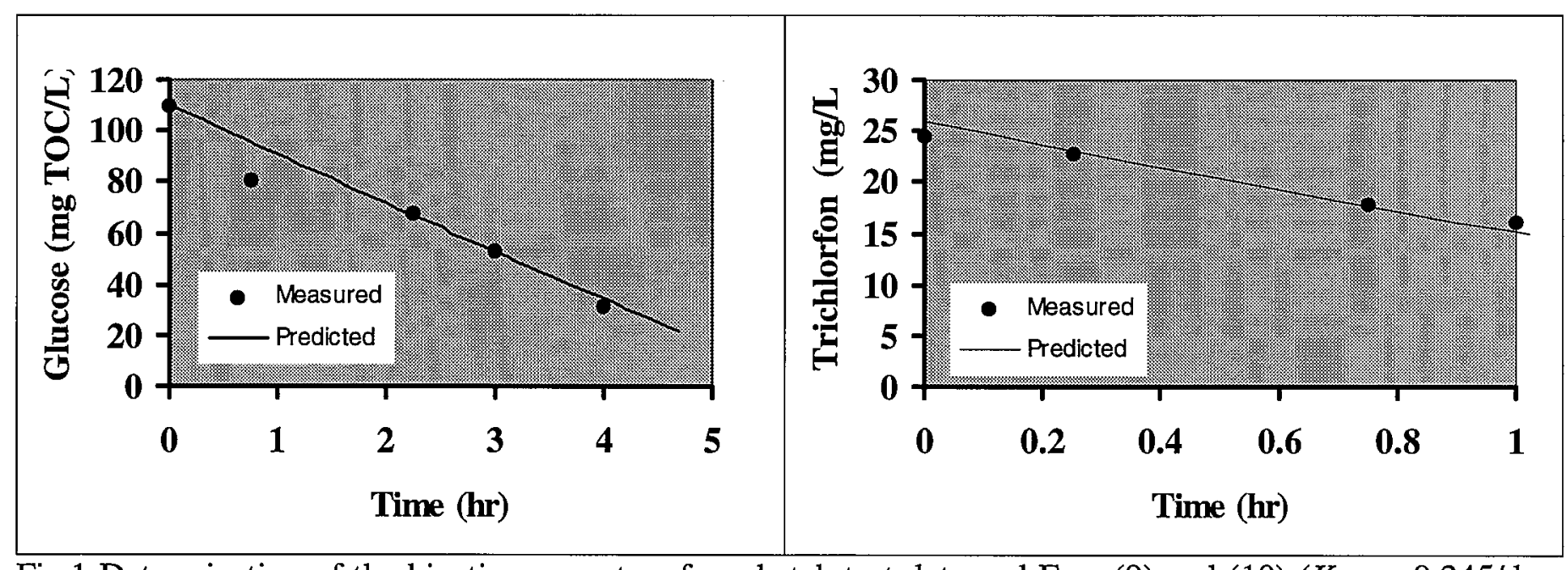

Fig.1 Determination of the kinetic parameters from batch test data and Eqs. (9) and (10) $\left(K_{g m s}=0.245 /\right.$ day; $K_{t m s}=0.228 /$ day; $K_{g s}=5 \mathrm{mg} / \mathrm{L} ; K_{t s}=15 \mathrm{mg} / \mathrm{L}$; and $X_{m}=2000 \mathrm{mg} / \mathrm{L}$ )

Some parameters in other two groups could be either estimated or taken from literature: the diffusivities of glucose and oxygen in the bulk liquid phase were taken from literature (Perry et al., 1963) while that of trichlorfon was estimated from its molecular size (Perry et al., 1963); the diffusivities of the substances within the attached phase were assumed to be $80 \%$ of those in the bulk liquid phase (Williamson and McCarty, 1976); the thickness of the diffusion layer and the yield coefficients of glucose and trichlorfon were assumed to be $100 \mu \mathrm{m}$ (Williamson and McCarty, 1976), 0.5 (Idei, 1990), and 0.1, respectively. The rest of the parameters in these two groups were measured directly, such as the concentrations of the suspended biomass, and the biomass density and the thickness of the attached phase (Ozaki et al., 1991, 1993) or are given in the simulation, such as the $A, Q, V$, bulk DO level, and the influent concentrations of the pollutants. A summary of the values of the parameters used for the model simulation is shown in Table 1.

\section{Example of Model Simulation Results}

Figure 2 shows an example of the model simulation results, which demonstrates that the proposed model and the analysis approach in this paper can give reasonable simulations on the simultaneous removal of trichlorfon and glucose in the hybrid bioreactor. By this model, effluent concentrations of both trichlorfon and glucose 
can be predicted under a specific removal condition, the model is, therefore, able to quantitatively evaluate the removal performance of both the biomass in a hybrid bioreactor under various removal conditions.

Table 1 The values of the parameters used in the model simulation

\begin{tabular}{cll}
\hline Parameter & \multicolumn{2}{c}{ Value } \\
\hline$A$ & $609 \mathrm{~cm}^{2}$ \\
$C$ & $5.0 \mathrm{mg} \mathrm{O}_{2} / \mathrm{L}$ \\
$L_{f}$ & $3 \quad \mathrm{~mm}$ \\
$L o$ & $100 \mu \mathrm{m}$ \\
$Q$ & $12.8 \mathrm{~L} /$ day \\
$S_{o g}$ & $150 \mathrm{mg} \mathrm{TOC} / \mathrm{L}$ \\
$S_{o t}$ & $25 \mathrm{mg} / \mathrm{L}$ \\
$V$ & $2.2 \mathrm{~L}$ \\
$X_{m}$ & $2000 \mathrm{mg} \mathrm{SS} / \mathrm{L}$ \\
$X_{f}$ & $11 \mathrm{mg} \mathrm{SS} / \mathrm{cm}^{3}$ \\
\hline
\end{tabular}

\begin{tabular}{cll}
\hline Parameter & \multicolumn{2}{c}{ Value } \\
\hline$D_{w c}$ & 2.16 & $\mathrm{~cm}^{2} /$ day \\
$D_{w g}$ & 0.60 & $\mathrm{~cm}^{2} /$ day \\
$D_{w t}$ & 0.42 & $\mathrm{~cm}^{2} /$ day \\
$K_{\text {gms }}$ & 0.245 & $/$ day \\
$K_{t m s}$ & $0.228 /$ day \\
$K_{s g}$ & 5.0 & $\mathrm{mg} \mathrm{TOC} / \mathrm{L}$ \\
$K_{s t}$ & 15.0 & $\mathrm{mg} / \mathrm{L}$ \\
$K_{o}$ & 0.1 & $\mathrm{mg} \mathrm{O} / \mathrm{L}$ \\
$P$ & 1.42 & $\mathrm{mg} \mathrm{COD} / \mathrm{mg} \mathrm{VSS}$ \\
$Y_{g}$ & 0.5 & $\mathrm{mg} \mathrm{VSS} / \mathrm{mg} \mathrm{COD}$ \\
$Y_{t}$ & 0.1 & $\mathrm{mg}$ VSS$/ \mathrm{mg} \mathrm{COD}$ \\
\hline
\end{tabular}

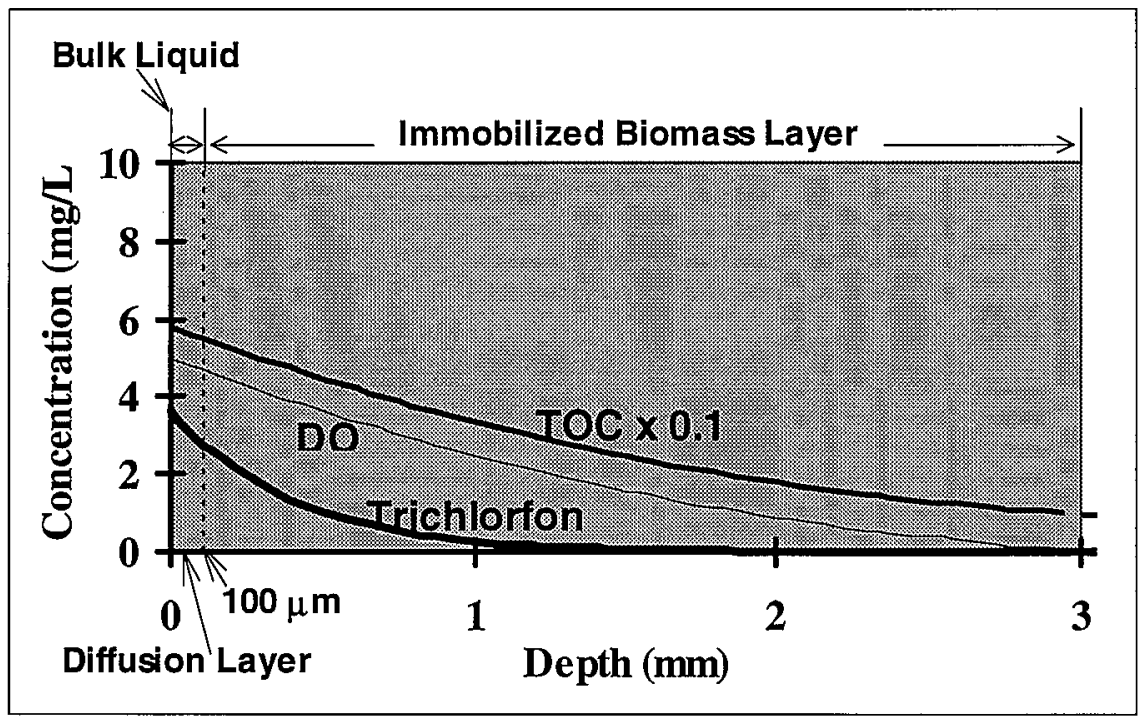

Fig. 2 An example of the model simulation results

\section{MODEL VERIFICATION}

To verify the proposed model, a hybrid bioreactor consisting of the suspended biomass and magnetically immobilized biomass, as shown in Fig. 3, was used in this study. By using such immobilized biomass, it is easier to alter the thickness and density of the attached biomass, and the weight ratio of the suspended biomass to the attached biomass (Sakai, et. al., 1992), which are extremely difficult to be regulated with a naturally attached growth. Therefore, extensive experiments for the model verification can be conducted under a variety of removal conditions in this study.

In this hybrid bioreactor, 147 pieces of a small permanent magnetic block possessing a magnetic strength of 3200 gauss were installed around the wall of the reactor as the magnetic support media. The media can effectively attract the biomass carrying magnetic powders $\left(\mathrm{Fe}_{3} \mathrm{O}_{4}\right)$ onto the surface of reactor walll. Thus, an immobilized biomass layer or a "magnetic biofilm", was formed by the "magnetic" biomass and the magnetic support media. Prior to the formation of such a biofilm, the magnetic biomass was prepared by a vigorous mixing between original suspended biomass and the magnetic powders in the reactor. The magnetic biomass was composed of 50\% magnetic powders and $50 \%$ biomass in a dried basis. A continuous attachment of the magnetic biomass was then initiated by a gently mixing. Within a shỡt period of time, a üniform attachiment 
of the biomass was developed on the inner wall surface of the reactor, as shown in Fig. 3. After the development of such magnetic biofilm, a certain amount of non-magnetic suspended biomass was added into this reactor to establish tow phases of biomass in the system.

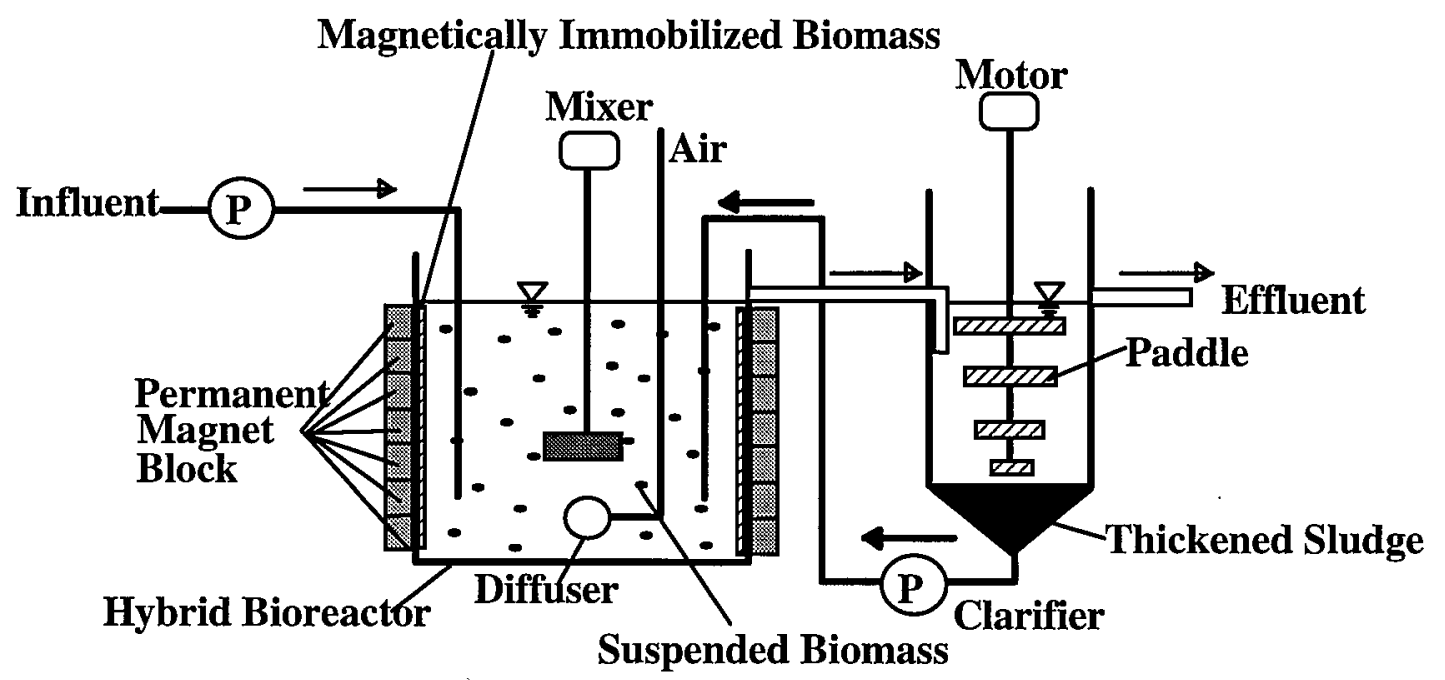

Fig 3. Experimental setup for continuous experiment

A set of continuous experiments using the above experimental setup was conducted in a temperature constant room $\left(20^{\circ} \mathrm{C}\right)$ under various removal conditions. Each experiment continued for around 90 hours to obtain a stable effluent. DO level and the suspended biomass concentration were controlled at 5-6 $\mathrm{mg} / \mathrm{L}$ and a fixed level, respectively. The actual reactor volume and the biofilm surface area were measured to be $2.13 \mathrm{~L}$ and $609 \mathrm{~cm}^{2}$. The hydraulic retention time was fixed at 4 hours for each experiment. The detail of the experimental conditions is shown in Table 2.

Table 2 Removal conditions in the continuous experiment

\begin{tabular}{cccccc}
\hline Run No. & $\begin{array}{c}\text { Influent Glucose } \\
(\mathrm{mg} \text { TOC/L) }\end{array}$ & $\begin{array}{c}\text { Influent Trichlorfon } \\
(\mathrm{mg} / \mathrm{L})\end{array}$ & $\begin{array}{c}\text { Suspended Biomass } \\
(\mathrm{mg} \mathrm{SS} / \mathrm{L})\end{array}$ & $\begin{array}{c}\text { Biofilm Density } \\
\left(\mathrm{mg} \mathrm{SS} / \mathrm{cm}^{3}\right)\end{array}$ & $\begin{array}{c}\text { Biofilm Thickness } \\
(\mathrm{mm})\end{array}$ \\
\hline 1 & 141 & 25.9 & 4000 & 0 & 0 \\
2 & 159 & 25.1 & 2000 & 11 & 3 \\
3 & 146 & 25.2 & 2000 & 13 & 5 \\
4 & 153 & 25.4 & 2000 & 18 & 7 \\
5 & 140 & 110.7 & 2000 & 11 & 3 \\
6 & 159 & 24.1 & $250^{*}$ & 13 & 5 \\
\hline
\end{tabular}

*: estimated value.

In this table, the densities were calculated from the amount of biomass used for forming the magnetic biofilm, the surface area of the biofilm formed, and the thickness measured. Based on these measurements and the values of other necessary parameters indicated in Table 1, the model predicted the simultaneous removal efficiencies of trichlorfon and glucose under each condition. The comparisons between the experimental results and the model predictions are shown in Fig. 4. The model predictions for each test run were well close to the experimental results. It can then be said that the proposed model is able to satisfactorily predict such removal efficiency in the hybrid bioreactor. This figure also shows that in this hybrid system, the simultaneous removal of trichlorfon and TOC is mainly due to the suspended biomass. This implies that an increase of a total biomass amount by introducing an attached biomass phase may not be very effective as both the suspended and attached biomass in this system contain the same pollutants removing microorganisms, and the advantage of the biofilm in removing slowly biodegradable substances cannot be utilized. However, when a substance having either a small maximum specific removal rate $\left(K_{t m s}\right)$ or a high diffusivity is introduced, the contribution of the biofilm can be maximized, as shown in Fig. 5. 


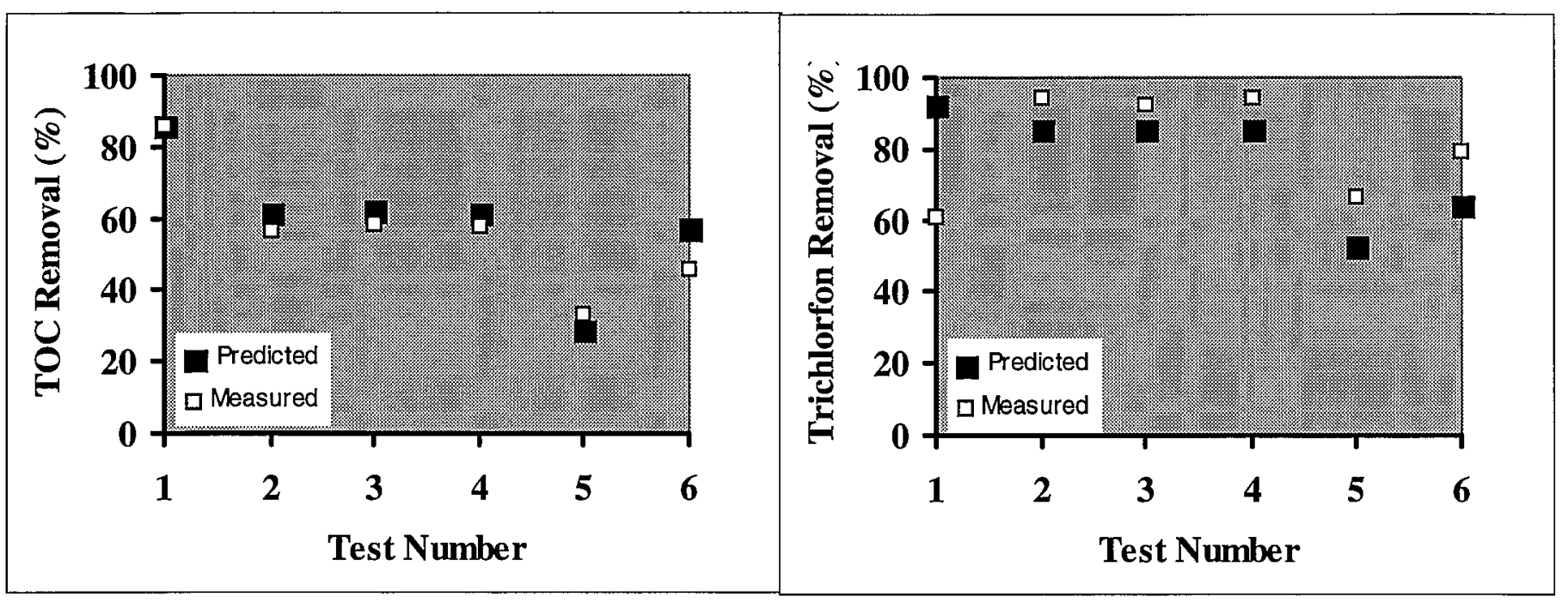

Fig. 4 Comparison of the experimental results with the model prediction

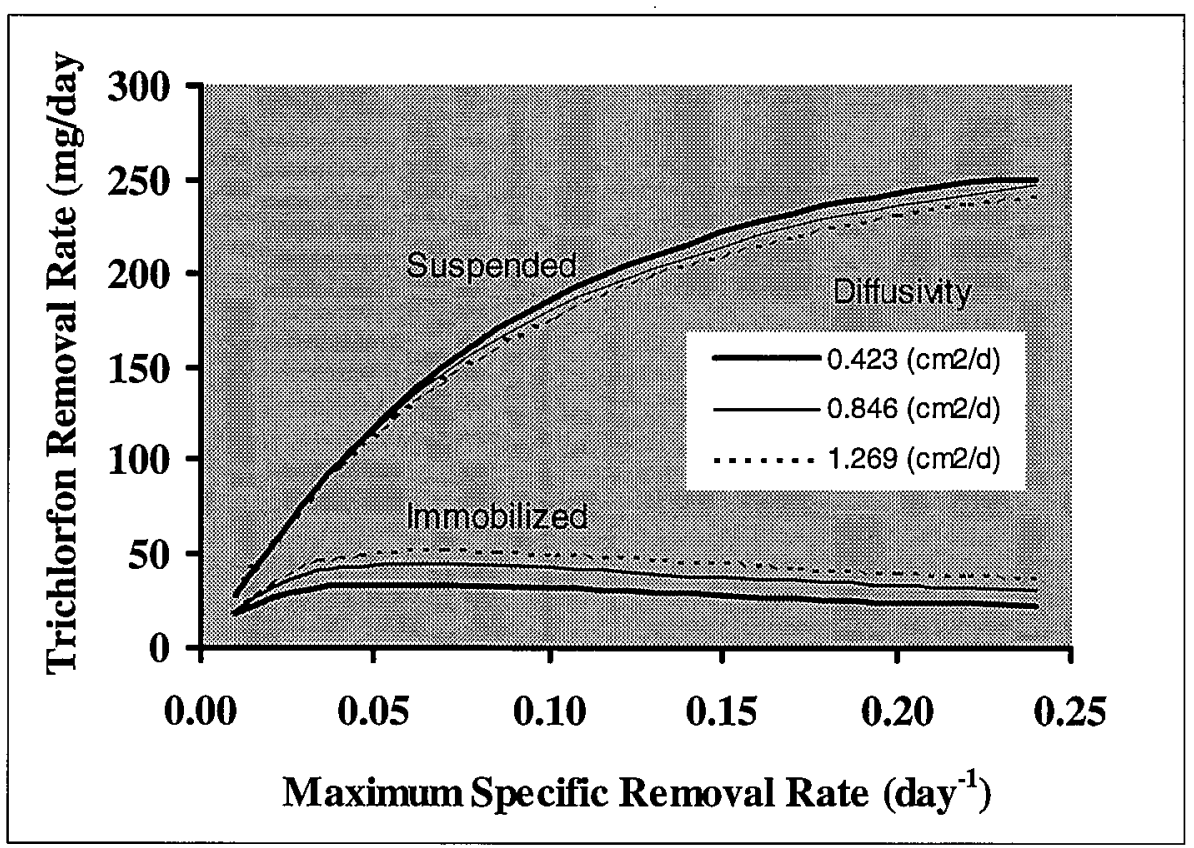

Fig. 5 Simulation on the effects of biodegradability and diffusivity of trichlorfon on its removal rate

This can be explained that a very slowly biodegradable substance usually requires a long contact time which can be achieved by a penetration of the substance in the biofilm (Chen, et al., 1997). On the other hand, since such a penetration is also influenced by the diffusivity of the substance, a high diffusivity is in favor of the removal rate in the biofilm. As a result, an overall removal of such a substance in a hybrid bioreactor is controlled by the biodegradability as well as the diffusivity. It can be seen from this figure that the biodegradability effects the removal rate more significantly than the diffusivity does. To effectively apply such a hybrid system in treating a complex wastewater containing both easily and slowly biodegradable pollutants, it is recommended to apply it to treat such complex wastewaters that contain very slowly biodegradable and highly diffusitive substances.

\section{CONCLUSION}

This paper has developed a mathematical model for predicting the simultaneous removal of trichlorfon and glucose in the hybrid bioreactor that contained a magnetically immobilized biomass phase.

The model has been verified well by the comparisons of the model predictions with the experimental results under various removal conditions. 
The suspended biomass has also been found to play a more important role in such simultaneous removal than the attached biomass does if both the biomass have the same pollutant removing microorganisms.

To maximize the removal capacity of the attached biomass, it is recommended to apply such a hybrid bioreactor to deal with a complex wastewater that contains much slowly biodegradable pollutants with a high diffusivity.

\section{ACKNOWLEDGMENT}

The authors wish to thank Dr. Lianfa Song for his advice on the numerical simulation work and the Hong Kong University of Science \& Technology for partial financial support (DAG95/96.EG15).

\section{REFERENCES}

Idei, T. (1990) Water treatment engineering-theory and practice (second edition, in Japanese), Gihodou Publisher, Tokyo.

International Agency for Research on Cancer (1983) Evaluation of the carcinogenic risk of chemicals to humans, Miscellaneous Pesticides, 30.

Chen, G. H., Ng, W. J., Ozaki, H., and Terashima, Y. (1994). Determination of dissolved oxygen limitation in aerobic biofilm reactors, Jour. of Resources, Conservation and Recycling, 11, 73-81.

Chen, G. H. (1995) Optimal removal conditions for simultaneous removal of easily and slowly biodegradable organics in a hybrid reactor, Proc. of 3rd IAWQ Specialized Conference on Design and Operation of Small Wastewater Treatment Plants for Tropical \& Subtropical Regions, Malaysia, 313321.

Chen, G. H. Chen, Huang, J. C., and Lo, M.C. I. (1997) Removal of rate-limiting organic substances in a hybrid biological reactor, Wat. Sci. \& Tech., 35(6), 81-89.

Horvath, R. S. (1972) Microbial co-metabolism and the degradation of organic compounds in nature, Bacteriological Reviews, June, 146-155.

Ozaki, H., Liu, Z., and Terashima, Y. (1991) Utilization of microorganisms immobilized with magnetic particles for sewage and wastewater treatment, Wat. Sci. \& Tech., 23, 1125-1136.

Ozaki, H. Terashima, Y., and Ishida, I. (1993) Wastewater treatment using magnetically immobilized biomass (in Japanese), Environ, Sanit. Eng. Res., 7(3), 216-221.

Orus, M. I. and Arco E. (1991) Disappearance of Trichlorfon from cultures with different cyanobacteria, Bull. Environ. Contam. Toxicol., 47(3), 392-397.

Perry, J. H., Perry, R. H., Chilton, C. H., and Kirkpatrick, S. D. (1963) Chemical engineers' handbook (fourth edition), McGraw-Hill Book Company, New York..

Primi, P., Surgan, M. H., and Urban, T. (1994) Leaching potential of turf pesticides: a case study of long island golf courses, Ground Water Monitor Remediation, 14(3), 129-139.

Samuelsen, O. B. (1987) Aeration rate, $\mathrm{pH}$ and temperature effects on the degradation of trichlorfon to DDVP and the half-lives of trichlorfon in seawater, Aquaculture, 66.

Sakai, Y., Hosokawa, O., and Takahashi, F. (1992) The fixed bed submerged filtration with using biofilm produced by magnetic attraction on the magnetic support media (in Japanese), Jour. of Japan Water Environment Association, 15(8), 527-533.

Williamson, K. and McCarty, P. L. (1976). A model of substrate utilization by bacterial films. J. Wat. Poll. Control Fed., 48, 9-24. 

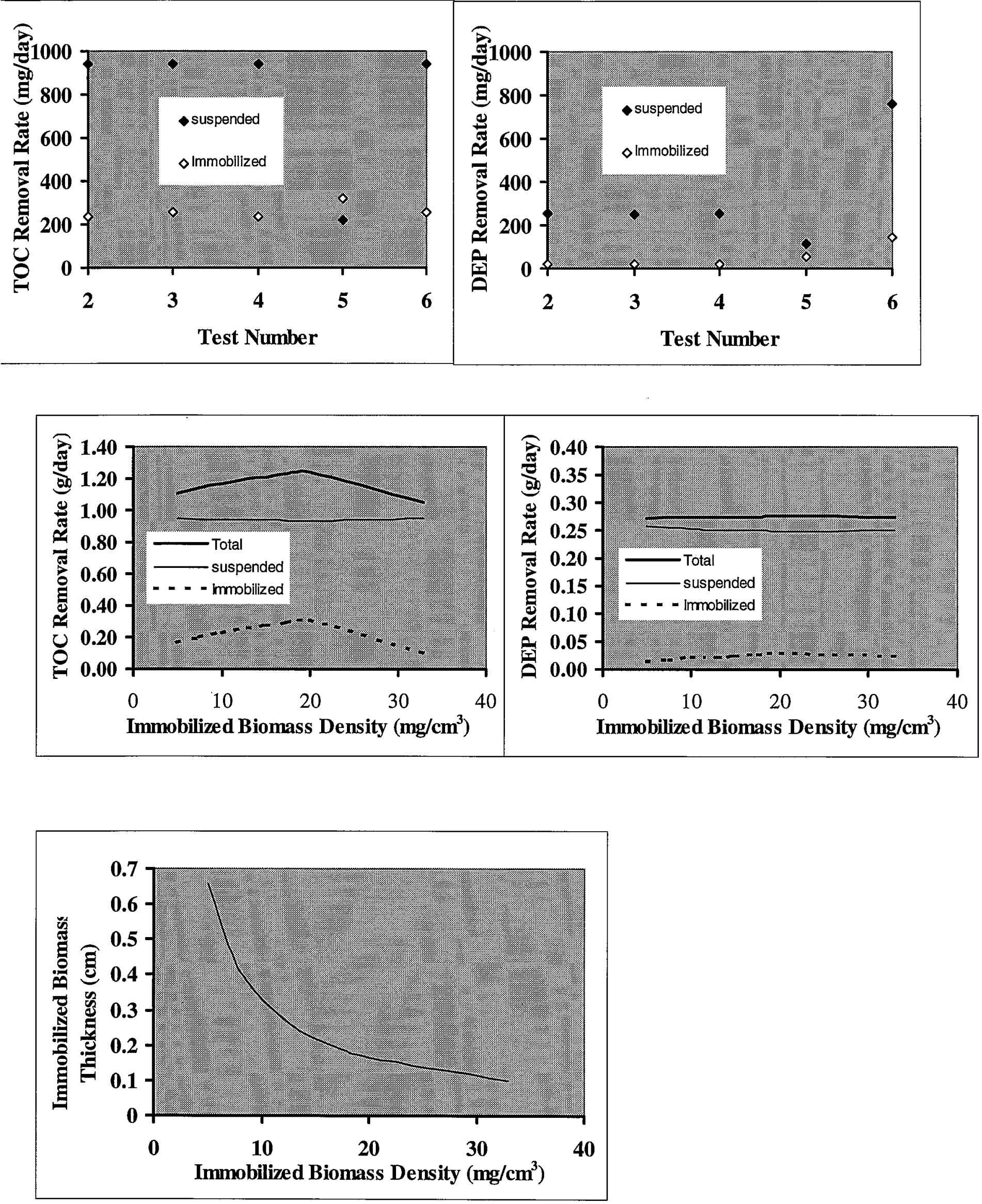